\title{
Bilateral Simultaneous Retinal Detachment in Pseudophakia
}

\author{
Patrick Paquet $^{\mathrm{a}} \quad$ Marie T. Fischer $^{\mathrm{a}}$ Peter Distelmaier $^{\mathrm{a}} \quad$ Antje Mammen ${ }^{\mathrm{a}}$ \\ Linda M. Meyer ${ }^{a} \quad$ Carl-Ludwig Schönfeld ${ }^{b}$ \\ ${ }^{a}$ Herzog Carl Theodor Eye Clinic, and ${ }^{b}$ Department of Ophthalmology, \\ Ludwig Maximilian University, Munich, Germany
}

\section{Key Words}

Retinal detachment - Ablatio - Bilateral retinal detachment .

Simultaneous retinal detachment. Pseudophakia

\begin{abstract}
Cataract surgery is the most frequent surgical intervention, with approximately 700,000 operations per year in Germany alone. One of the most serious complications is retinal detachment, with a reported incidence rate of pseudophakic retinal detachment of $0.75-1.65 \%$. We report the case of a patient who suffered from a simultaneous bilateral pseudophakic retinal detachment. Interestingly, the bilateral detachments in the left and the right eye started with only some hours' delay. He had no acute trigger for the retinal detachment and no risk factors besides the cataract surgery performed on both eyes some weeks earlier. Simultaneous bilateral retinal detachments will be more common, due to increasing numbers of cataract surgeries and the demographic development. We conclude that funduscopy should be regularly performed in mydriasis to avoid sight-threatening simultaneous bilateral retinal detachments.

(c) 2015 S. Karger AG, Basel
\end{abstract}

\section{Introduction}

Cataract surgery is the most frequent surgical intervention, with approximately 700,000 operations per year in Germany alone. One of the most serious complications is retinal detachment (RD), with a reported incidence rate of pseudophakic RD of $0.75-1.65 \%$ [1]. The rate of $\mathrm{RD}$ in the fellow eye is reported in textbooks to be $10 \%$ in phakic patients and $20-$ $36 \%$ in pseudophakic patients [2]. Further risk factors for RD are higher age, myopia or trauma [3-7]. 
Paquet et al.: Bilateral Simultaneous Retinal Detachment in Pseudophakia

We report the case of a patient who suffered from a simultaneous bilateral pseudophakic RD. Interestingly, the bilateral detachments in the left and the right eye started with only some hours' delay. He had no acute trigger for the RD and no risk factors besides the cataract surgery performed on both eyes some weeks earlier.

\section{Case Report}

A 61-year-old male Caucasian experienced floaters in his left eye. Four days later, his ophthalmologist diagnosed RD and referred him to our department for surgery. One month previously, phacoemulsification and implantation of a posterior chamber intraocular lens had been performed on both eyes without intraoperative or postoperative complications. His medical history included colon carcinoma, which had been treated by hemicolectomy and chemotherapy. The patient did not take any medication at the time of admission.

On the day of referral, the patient showed a best corrected visual acuity of $0.2 \operatorname{logMAR}$ in his right eye and $0.5 \operatorname{logMAR}$ in his left eye. The intraocular pressure was 16 and $19 \mathrm{~mm} \mathrm{Hg}$, respectively. A slit-lamp examination showed regular pseudophakia in both eyes. There were signs of irritation in both eyes, with a positive Tyndall phenomenon but no cells. Vitreous examination revealed cells in both eyes. In the right eye, the retina was attached. In the left eye, a 150-degree RD was seen starting from 7 o'clock with a horseshoe tear at 11 o'clock. The patient was admitted to the ward and positioned supinely. Pars plana vitrectomy (PPV) was scheduled for the following day. The next morning, before surgery, the patient reported newfound floaters in his right eye. On examination, a 90-degree RD in the right eye was diagnosed starting at 9 o'clock with a small horseshoe tear at 11 o'clock.

On the same day, a 23-gauge PPV was performed using perfluorodecalin, endolaser coagulation and a $20 \%$ hexafluoroethane $\left(\mathrm{C}_{2} \mathrm{~F}_{6}\right)$ gas tamponade on the patient's left eye. The next day, PPV was performed on his right eye using the same surgical approach. There were no intra- or postoperative complications.

A follow-up visit 1 month later revealed a best corrected visual acuity of $0.1 \log$ MAR in the right eye and $0.2 \operatorname{logMAR}$ in the left eye. The retinas were attached in both eyes.

\section{Discussion}

We here reported a unique case of simultaneous bilateral pseudophakic RD which occurred only some hours apart. The patient experienced symptoms in both eyes. Phacoemulsification and posterior chamber intraocular lens implantation had been performed 1 month earlier.

A literature review reveals some studies focusing on simultaneous bilateral RD (SBRD). A retrospective study by Krohn and Seland [3] from Norway showed that 2.3\% of the RDs operated by them between 1990 and 1998 were bilateral and simultaneous. They had an overall annual incidence of RD cases of 16.2 per 100,000. The overall annual incidence of SBRDs was 0.35 cases per 100,000. A study from Germany [4] revealed a $1.18 \%$ SBRD rate among their 931 cases of RD. A study by El Matri et al. [5] showed a 1.5\% SBRD rate among 497 surgeries due to RD. Dotrelová et al. [6] reported similar results with 1.4\% SBRD. Thus, SBRD does not seem to be very rare. All previously cited papers do not comment about the interval between first diagnoses of RD in the right and the left eye. To our knowledge, ours is the first report about simultaneous RD in pseudophakia that occurred within $24 \mathrm{~h}$. 
Paquet et al.: Bilateral Simultaneous Retinal Detachment in Pseudophakia

The abovementioned studies [3-6] demonstrate that patients with SBRD typically are young, are myopic and have multiple round retinal holes. Our patient, in contrast, was 61 years old and emmetropic before cataract surgery. The reported cumulative risk of RD following cataract surgery is about 2.3 times the natural incidence [5]. With increasing numbers of cataract surgery, it may be expected that SBRD will become more likely.

We conclude that funduscopy should be regularly performed in mydriasis to avoid sightthreatening SBRD. SBRD will be more common, due to increasing numbers of cataract surgery and the demographic development.

\section{Statement of Ethics}

The authors have no ethical conflicts to disclose.

\section{Disclosure Statement}

The authors declare that they have no financial interests and nothing to disclose regarding this case report.

\section{References}

1 Ramos M, Kruger EF, Lashkari K: Biostatistical analysis of pseudophakic and aphakic retinal detachments. Semin Ophthalmol 2002;17:206-213.

2 Regillo CD: Basic and Clinical Science Course, Section 12: Retina and Vitreous. San Francisco, American Academy of Ophthalmology, 2011.

-3 Krohn J, Seland JH: Simultaneous, bilateral rhegmatogenous retinal detachment. Acta Ophthalmol Scand 2000;78:354-358.

4 Bodanowitz S, Hesse L, Kroll P: Simultaneous bilateral rhegmatogenous retinal detachment (in German) Klin Monbl Augenheilkd 1995;206:148-151.

5 El Matri L, Mghaieth F, Chaker N, Kamoun M, Charfi O, Chaabouni A: Simultaneous bilateral rhegmatogenous retinal detachment. 7 case studies (in French). J Fr Ophtalmol 2004;27:15-18.

-6 Dotrelová D, Bedrich P, Gergelyová K, Moravcová Z, Dolezalová J, Resslová D: Bilateral retinal detachment (in Czech). Cesk Oftalmol 1993;49:351-361.

7 Olsen T, Jeppesen P: The incidence of retinal detachment after cataract surgery. Open Ophthalmol J 2012;6:79-82. 